Arq. Bras. Med. Vet. Zootec., v.71, n.1, p.291-302, 2019

\title{
Características físicas e microbiológicas de compostagem de resíduos animais
}

[Physical and microbiological characteristics process of composting waste from animals]

\author{
H.A. Souza ${ }^{1}$, E.L. Oliveira ${ }^{2}$, P.Y. Faccioli-Martins ${ }^{2}$, L. Santiago ${ }^{3}$, A.A. Primo ${ }^{4}$, \\ M.D. Melo ${ }^{5}$, G.A.C. Pereira \\ ${ }^{1}$ Embrapa Meio-Norte - Teresina, PI \\ ${ }^{2}$ Embrapa Caprinos e Ovinos - Sobral, CE \\ ${ }^{3}$ Médica veterinária autônoma - Ibiá, MG \\ ${ }^{4}$ Universidade Federal do Ceará - Fortaleza, CE \\ ${ }^{5}$ Universidade Estadual Vale do Acaraú - Sobral, CE
}

\begin{abstract}
RESUMO
Objetivou-se com o presente trabalho caracterizar o processo de compostagem de fluxo contínuo e aeração passiva de resíduos da produção e abate da caprino-ovinocultura e de seu composto orgânico gerado. O processo de compostagem utilizou resíduos sólidos provenientes da produção e do abate de caprinos e ovinos e foi realizado em galpão de alvenaria. Os resíduos agropecuários utilizados incluíram sobras de capim-elefante triturado seco, poda de árvores, esterco e carcaça de caprinos e ovinos. Os tratamentos empregados foram três níveis de umidade aplicados nas leiras de compostagem (30, 50 e $70 \%$ com base no peso da carcaça dos animais) e épocas do ano de montagem (período seco, transição e úmido) com base na precipitação, com três repetições. As variáveis avaliadas foram atributos químicos, físicos, microbiológicos e parasitológicos do composto e sua comparação com a legislação vigente. $\mathrm{O}$ composto orgânico gerado atende as especificações das legislações utilizadas para comparação. Independentemente da época do ano ou da umidade aplicada, o processo de compostagem foi eficiente em reduzir passivos ambientais, como carcaças. A compostagem promoveu a eliminação dos patógenos avaliados, indicando que o composto não oferece risco de transmissão e pode ser utilizado de forma segura.
\end{abstract}

Palavras-chave: caprinos, ovinos, subprodutos

\begin{abstract}
The objective of this study to characterize the process of continuous flow of composting and passive aeration of waste production and slaughter the goat and sheep industry and its generated organic compound. The composting process, performed in a brick barn, used solid residues (manure and carcass parts) from the slaughter of goats and sheep along with chopped dry elephant grass and tree trimmings. The treatments employed three moisture levels in the piles and four collections of samples from the piles at timed intervals $(0,30,60$ and 120 days), with three repetitions. The variables evaluated were the chemical and physical attributes of the compost generated. The treatments were three moisture levels applied in compost piles (30, 50 and 70\% based on the housing of animals) and assembly times of the year (dry, transitional and humid) based on rainfall, with three replications. The variables were chemical, physical, microbiological and parasitological of the compound and its comparison with current legislation. The generated organic compound meets the specifications of the laws used for comparison. Regardless of the time of year or moisture applied, the composting process was effective in reducing environmental liabilities as carcasses. Composting promoted elimination of this pathogen, indicating that the compound can be used safely.
\end{abstract}

Keywords: goats, sheeps, byproduct

Recebido em 17 de fevereiro de 2017

Aceito em 9 de julho de 2018

E-mail: henrique.souza@embrapa.br 


\section{INTRODUÇÃO}

No Brasil, existem mais de 25,4 milhões de caprinos e ovinos (Anuário..., 2014). A região Nordeste do país responde pelo maior número de cabeças, com participação superior a $90 \%$ para caprinos e a $60 \%$ para ovinos, sendo esta uma das principais atividades agropecuárias da região, especialmente para a agricultura familiar (Souza et al., 2015).

Como nas demais atividades agropecuárias, a caprinocultura e a ovinocultura são geradoras de resíduos que, se bem manejados, poderão tornarse não apenas uma importante fonte de renda e agregação de valor à atividade mas também um modelo de produção sustentável que vem tornando-se cada vez mais uma exigência de mercado. Para tanto, é necessário que haja a adoção de um sistema de tratamento desses resíduos a fim de evitar possíveis contaminações do ambiente (Angonese et al., 2006).

O emprego da compostagem como meio de sanitização e fim adequado para tratamento de carcaças da produção animal é alternativa interessante e já utilizada, por exemplo, para a cadeia da avicultura, Orrico Júnior et al. (2010) avaliaram o processo de compostagem de carcaça de aves e concluíram ser um método eficiente para tratamento e aproveitamento desses resíduos; de maneira análoga para suínos (Murray et al., 2007) e bovinos (Curci et al., 2007; Otenio et al., 2010) resultados indicam a compostagem como alternativa para o tratamento desses subprodutos da produção animal.

Conforme Valente et al. (2009), a compostagem é um processo de decomposição aeróbia controlada e de estabilização da matéria orgânica em condições, que permite o desenvolvimento de temperaturas termofílicas, resultantes de uma produção calorífica de origem biológica, com obtenção de produto final estável, sanitizado, rico em compostos húmicos e cuja utilização no solo não oferece riscos ao meio ambiente.

Não há, na legislação brasileira, parâmetros relacionados às características microbiológicas ou físicas do processo de compostagem de resíduos animais. Alguns trabalhos utilizam as características preconizadas na Resolução 375/2006 do Conselho Nacional de Meio Ambiente - Conama (Heck et al., 2013). Em avaliação de diversos sistemas de aeração, Costa et al. (2006) estudaram leiras e composteiras à base de carcaças de aves com e sem aeração e concluíram que o desempenho dos sistemas foi satisfatório. Ainda, dentre os fatores que afetam o processo de compostagem, a umidade é indispensável para as atividades metabólica e fisiológica dos microrganismos. Valente et al. (2009) citam que valores entre 40 e $70 \%$ de umidade são empregados para decompor carcaças de animais. Outra questão que pode ser suscitada é que, em regiões semiáridas, que apresentam duas estações distintas (seca e chuvosa), a umidade relativa do ar pode influenciar o processo de compostagem ou a quantidade de água a ser empregada para o início do processo.

Considerando que, para o processo de compostagem, a umidade é fator preponderante para a devida sanitização do material compostado, acredita-se que diferentes umidades empregadas em sistemas de aeração passiva podem alterar características físicas $\mathrm{e}$ microbiológicas do processo. Assim, objetivouse avaliar umidades aplicadas em pilhas de compostagem de resíduos de pequenos ruminantes em diferentes épocas do ano, em Sobral-CE, a fim de se estudarem os efeitos nas características físicas e microbiológicas.

\section{MATERIAL E MÉTODOS}

O presente trabalho foi realizado no setor de compostagem da Embrapa Caprinos e Ovinos, localizada no município de Sobral-CE, em três períodos, sendo transição, de abril a agosto de 2012; seco, de setembro a dezembro de 2012; e chuvoso, de março a julho de 2013. A precipitação pluviométrica no período está apresentado no Fig. 1.

O processo de compostagem utilizou resíduos sólidos provenientes da produção e do abate de caprinos e ovinos e foi realizado em galpão de alvenaria de $128 \mathrm{~m}^{2}$, com revestimento de piso cimentado e cobertura em telhado colonial. As celas de compostagem foram construídas com 3,5 (largura) x 2,0 (profundidade) x 1,60m de altura, montadas por encaixe de tábuas em canaletas confeccionadas em pilar de madeira. As pilhas de composto foram trabalhadas em carregamento contínuo com aeração passiva, ou 
seja, não há revolvimento da leira em razão da não exposição das carcaças, e a aeração ocorre por convecção; adicionalmente, a água é inserida somente sobre as carcaças no momento de montagem da pilha. A primeira camada de cada pilha, ou seja, aquela que cobre o piso cimentado no interior da cela, foi formada por $0,40 \mathrm{~m}$ de material estruturante (mistura de $50 \%$ de esterco caprino e ovino e $50 \%$ de rejeitado de comedouros - capim-elefante triturado seco ou poda de árvore seca) em toda sua extensão interna. A segunda camada corresponde às carcaças e ao despojo sólido de abate, colocados em linha a $0,20 \mathrm{~m}$ de distância das paredes laterais e entre si, seguida do acréscimo de 30, 50 ou $70 \%$ de água, correspondente ao seu peso total. A terceira camada foi formada por $0,40 \mathrm{~m}$ de material estruturante, que cobriu completamente todas as carcaças na extensão interna da cela e ainda serviu de base para colocação da próxima camada de carcaças e despojo sólido de abate.

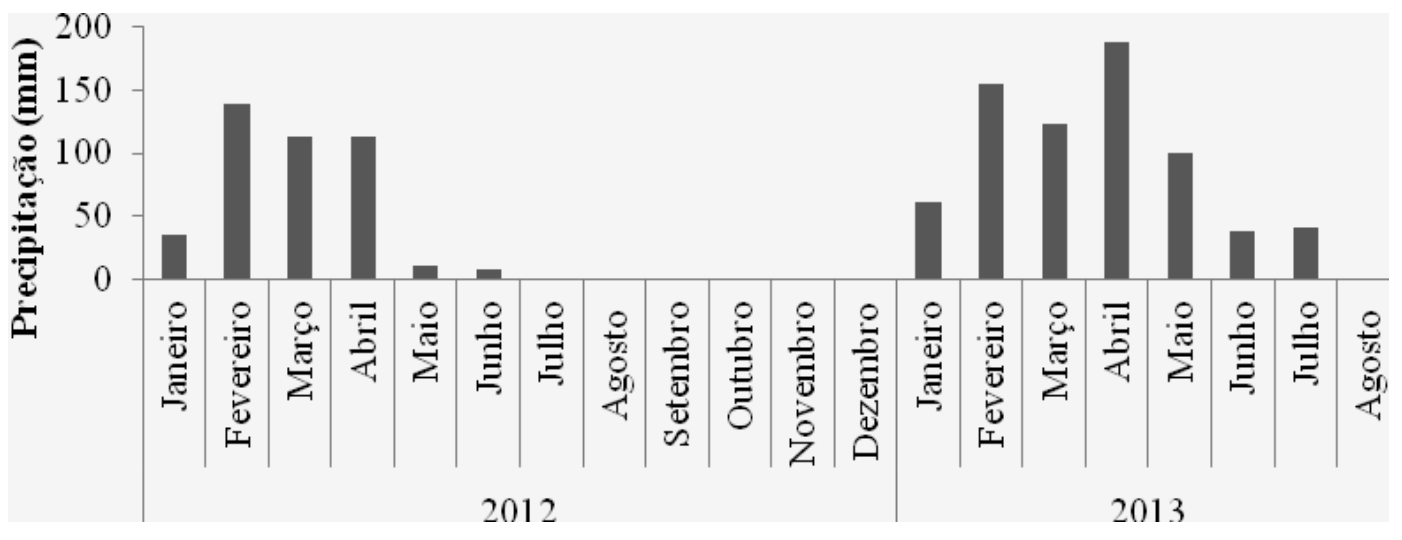

Figura 1. Precipitação pluviométrica em Sobral, no período de condução do ensaio. Fonte: www.funceme.br.

A terceira camada de cobertura foi formada pelo mesmo resíduo. As demais pilhas foram formadas sucessivamente, totalizando quatro camadas de material estruturante e três camadas de carcaças e despojo de abate sólido até o fechamento completo atingir a altura máxima da cela, sendo a última camada sempre da mistura de resíduo de estrume e materiais vegetais. $\mathrm{O}$ período de compostagem é de aproximadamente 120 dias, momento em que foram desmontadas as pilhas. $\mathrm{O}$ sistema de carga contínua e aeração passiva também é empregado em tratamento de carcaças de frangos, conforme preconizado por Abreu et al. (2011).

Os tratamentos empregados foram os níveis de água aplicados (30, 50 ou 70\%) com base no peso da carcaça do pequeno ruminante, bem como as épocas de montagem das pilhas (transição, seca e chuvosa) dentro de um ano (Fig. 1), com três repetições, constituindo, portanto, um esquema fatorial em parcelas subdivididas, sendo as parcelas as umidades, e as subparcelas os períodos. Os valores médios utilizados de carcaça, substrato e água em cada tratamento estão apresentados na Tab. 1.
As variáveis mensuradas foram a temperatura da pilha e a umidade relativa do ar, diariamente, sendo a temperatura a média de duas coletas no mesmo dia em cada pilha. Uma mensuração foi realizada no centro da pilha, com auxílio de um termo-higrômetro, e a outra a 30 centímetros da superfície superior, com auxílio de termômetro Datalogger, HOBOWarePro-2010 ${ }^{\circledR}$ de mercúrio (variação entre $5^{\circ} \mathrm{C}$ a $100^{\circ} \mathrm{C}$ ); a umidade relativa foi mensurada pelo termo-higrômetro.

Calcularam-se a redução em porcentagem da massa de carcaça e a massa da pilha de compostagem, com pesagens no início (Tab. 1) e na desmontagem das pilha (120 dias). De posse desses resultados e do valor de máxima temperatura verificada, procedeu-se à análise de variância e, quando significativo, empregou-se o teste de médias; para as temperaturas e a umidade relativa do ar em função do tempo de compostagem, empregou-se análise de regressão, testando-se os modelos linear, quadrático e pico lognormal. A análise de variância foi realizada com auxílio do software Sisvar (Ferreira, 2011). 
Tabela 1. Valores médios de massa de carcaça dos animais (caprinos e ovinos), substrato (restos de capim-elefante refugado no cocho, esterco caprino e ovino, e aparas de poda de árvore) e quantidade de água aplicada (em função da massa de carcaças) em cada época avaliada

\begin{tabular}{|c|c|c|c|}
\hline Umidade $^{1}$ & Carcaça $^{2}$ & Substrato & $\mathrm{H}_{2} \mathrm{O}$ \\
\hline$\%$ & \multicolumn{2}{|c|}{---------- kg ---------- } & $\mathrm{L}$ \\
\hline \multicolumn{4}{|c|}{ Transição (abril a julho de 2012) } \\
\hline 30 & 282 & 797 & 84 \\
\hline 50 & 220 & 756 & 110 \\
\hline 70 & 218 & 756 & 152 \\
\hline \multicolumn{4}{|c|}{ Seca (setembro a dezembro de 2012) } \\
\hline 30 & 294 & 595 & 88 \\
\hline 50 & 235 & 599 & 118 \\
\hline 70 & 247 & 476 & 173 \\
\hline \multicolumn{4}{|c|}{ Úmida (fevereiro a maio de 2013) } \\
\hline 30 & 233 & 756 & 70 \\
\hline 50 & 310 & 888 & 155 \\
\hline 70 & 149 & 737 & 104 \\
\hline
\end{tabular}

Nota: ${ }^{1} \mathrm{~A}$ umidade representa a porcentagem de água a ser adicionada em função do peso total das carcaças (na pilha de compostagem). ${ }^{2} \mathrm{O}$ valor é o total de animais postos na pilha de compostagem; o valor médio de cada carcaça era de $20-30 \mathrm{~kg}$.

Os testes microbiológicos e parasitológicos foram realizados em diferentes pontos da pilha, denominados fundo (F), meio (M) e superfície (S), com auxílio de um trado, sendo denominadas de fundo as amostras coletadas de 40 a $80 \mathrm{~cm}$ (desconsiderando-se a primeira camada, que é de material estruturante), meio, aquelas de 80 a $120 \mathrm{~cm}$, e superfície, as amostras coletadas acima de $120 \mathrm{~cm}$ do topo para a base da pilha com base na altura de montagem destas. As variáveis microbiológicas mensuradas foram coliformes termotolerantes e Salmonella sp., utilizando-se 150 gramas de amostra composta das três repetições (50 gramas) de cada tratamento. A partir de 10 gramas de amostra composta, foi feita a diluição $10^{-1}$ pela sua homogeneização em $90 \mathrm{~mL}$ de água peptonada e subsequentemente as diluições $10^{-2}$ e $10^{-3}$. Os coliformes termotolerantes foram detectados pelo método do número mais provável (NMP), conforme Kornacki e Johnson (2001), utilizandose caldo lauril sulfato triptose, suplementado com 4-metil-umbeliferil- $\beta$-D-glucuronídeo (LSTMUG) e caldo E. coli (EC), ambos contendo tubos de Durhan. A detecção de Salmonella sp. foi realizada segundo Andrews e Hammack (2007), por meio de enriquecimento seletivo em caldo tetrationato (TT) e Rappaport-Vassiliadis (RV), seguido de plaqueamento em ágar de desoxicolato-lisina-xilose (XLD) e ágar entérico de Hektoen (HE).

A análise parasitológica foi realizada pela contagem de ovos viáveis de helmintos, seguida de coprocultura, de 45 gramas de amostra composta das três repetições (15 gramas) de cada tratamento, sendo a amostra composta processada de acordo com Gordon e Whitlock (1939). Em algumas amostras parasitológicas, não foram visualizados ovos de helmintos, mas na coprocultura foram identificadas larvas de Strongyloides de vida livre. Nesses casos, interpretaram-se amostras com a visualização de até sete larvas como contagem de $<0,25$ ovo g ${ }^{-1}$ de sólidos totais (ST), e amostras com mais de sete larvas foram consideradas aquelas com contagem superior a 0,25 ovo $\mathrm{g}^{-1}$ de ST. De posse dos resultados, compararam-se os dados obtidos com o preconizado na Resolução $\mathrm{n}^{\circ}$ 375/2006 do Conama para lodo de esgoto, por não haver legislação vigente para resíduos animais.

Ainda, coletou-se uma amostra simples ao fim de cada período e umidade estudada para formar uma amostra composta com posterior secagem em estufa, e foi executada análise química de macro e micronutrientes, metais pesados, 
capacidade de troca catiônica, sólidos voláteis e pH, conforme Abreu et al. (2006). Em seguida, procedeu-se à comparação com os limites preconizados na Resolução $\mathrm{n}^{\circ}$ 375/2006 do Conama e na Instrução Normativa $\mathrm{n}^{\circ} 25$, de 2009, do Ministério de Agricultura, Pecuária e Abastecimento - Mapa.

\section{RESULTADOS E DISCUSSÃO}

Na Fig. 2 e na Tab. 2, estão apresentados os comportamentos da temperatura e da umidade relativa do ar nos períodos e níveis de umidades trabalhados. No período considerado de transição, que tangencia o fim do período chuvoso e o início do período seco (Fig. 1), para as três quantidades de água aplicadas em função da massa de carcaça, houve comportamentos similares, com aumento da temperatura e posterior diminuição com o passar dos dias. A umidade relativa apresentou comportamento similar ao verificado para a temperatura, que pode ser associado à saída do período chuvoso com diminuição da precipitação (Fig. 1). De maneira análoga para temperatura e inversa para umidade relativa do ar do período seco em relação ao de transição, há uma coincidência do comportamento da temperatura com aumento nos primeiros dias e decréscimo com o passar do tempo, e, para umidade relativa do ar, aumento com o fim do período de compostagem, em razão da aproximação do período chuvoso (Fig. 1). Para a estação considerada chuvosa, em relação ao desempenho da temperatura, verifica-se que há maior distinção dos comportamentos em função dos níveis de umidade estudados, com maiores temperaturas observadas na seguinte ordem decrescente: $50>30>70 \%$ (Fig. 2). O menor valor constatado para o nível de $70 \%$ pode ser justificado pela maior umidade relativa do ar no período, o que pode ter criado um excesso de umidade no material compostado, não sendo possível, assim, atingir patamares de temperatura maiores que $55^{\circ} \mathrm{C}$ (valor observado e valor estimado de $54,8^{\circ} \mathrm{C}$ ); para a umidade relativa do ar, esta apresentou decaimento com o passar do processo de compostagem, o que está em consonância com a precipitação verificada no período (Fig. 1); de maneira geral, para o período chuvoso, pode-se mencionar que houve aumento da temperatura nos primeiros dias, com decréscimo do período de compostagem estando de acordo com o observado nas demais épocas.

Durante o processo de compostagem, sobretudo no início do curso, são presentes bactérias mesofílicas, inerentes aos materiais orgânicos presentes nas pilhas, sendo alterados os microorganismos predominantes, que contribuem com a evolução do $\mathrm{CO}_{2}$, à medida que a temperatura sobe; bactérias termofílicas, principalmente na fase inicial de $60^{\circ} \mathrm{C}$ e, posteriormente, actinomicetos termofílicos, os quais são mais efetivos na busca de nutrientes em condições de baixos níveis, que se expressam em temperaturas altas. Ainda, fungos termofílicos não são detectados em altas taxas de umidade, sendo as temperaturas ideais de 45 a $50^{\circ} \mathrm{C}$ (Miytake e Iwabuchi, 2006).

Alguns autores citam que a manutenção da temperatura na faixa termofílica é em razão da degradação da matéria orgânica, o que pode ser considerado essencial para o tratamento de resíduos (Orrico et al., 2007; Valente et al., 2009). Em revisão sobre a compostagem de resíduos orgânicos, Valente et al. (2009) comentam que temperaturas superiores a $50^{\circ} \mathrm{C}$ proporcionam condições desfavoráveis para a sobrevivência e o desenvolvimento de microorganismos patogênicos.

Dentre os resultados obtidos, ressalta-se o desempenho das temperaturas verificadas na época seca, quando, mesmo com a baixa umidade relativa do ar, as pilhas apresentaram valores altos de temperatura no início do processo, com decréscimo com o passar do tempo (Fig. 2).

Para o fator umidade, houve maior redução da massa compostada com o emprego de $70 \%$ da quantidade de água em relação ao peso de carcaças, e, para o fator período, a maior redução foi verificada na época de transição (Tab. 3). 
a)

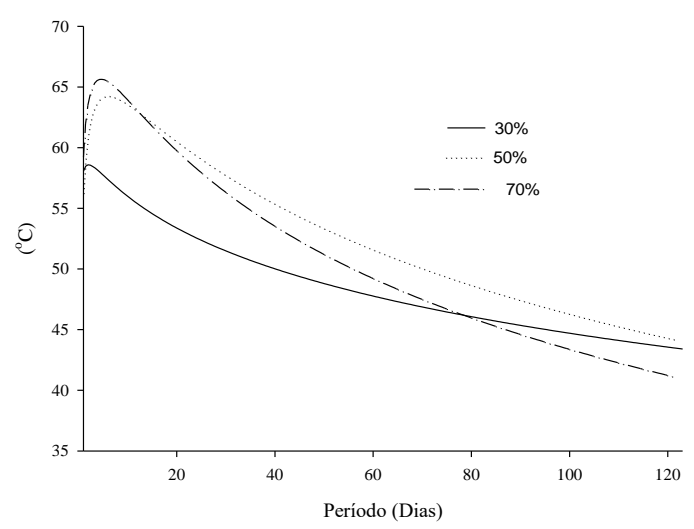

c)

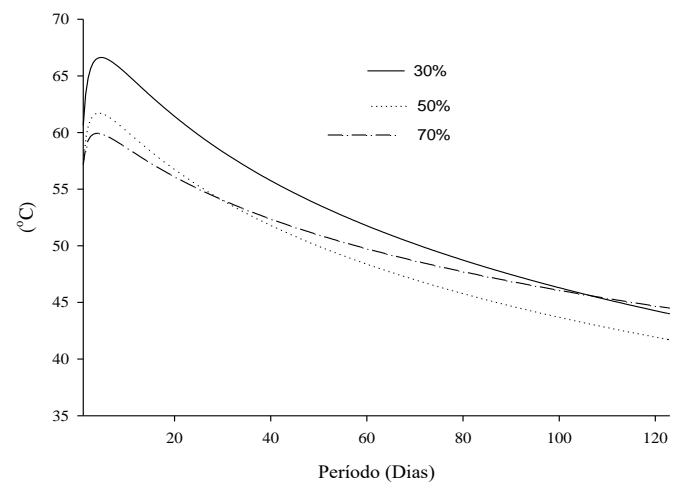

e)

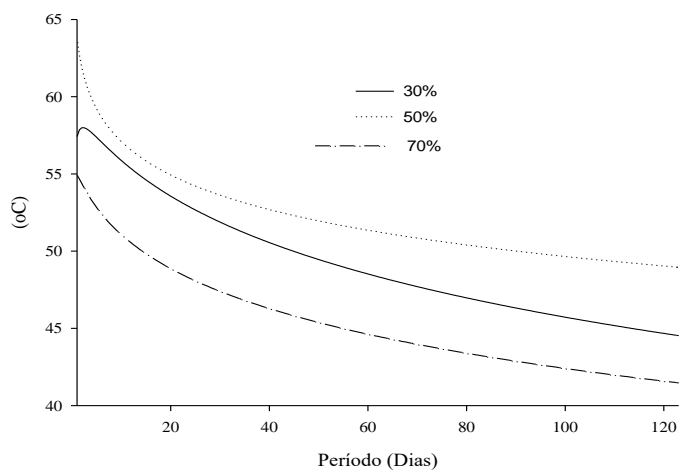

b)

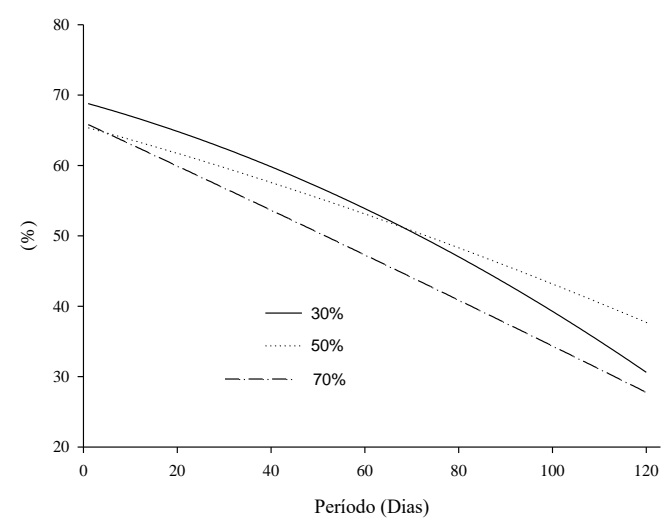

d)

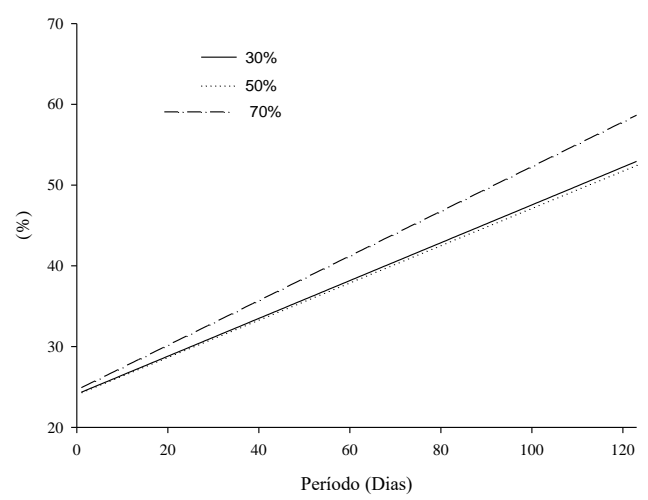

f)

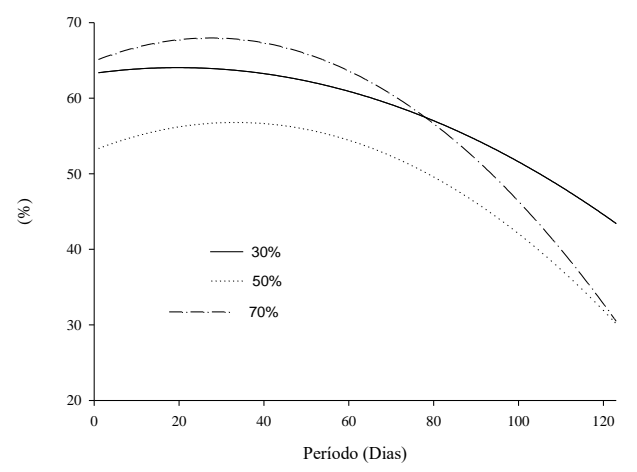

Figura 2. Temperatura e umidade relativa do ar para o período de transição $(a$ e $b$ ), para o período seco ( $c$ e $d$ ) e para o período chuvoso (e e $f$ ), respectivamente, em função de níveis de umidade aplicados nas pilhas de compostagem. 
Características físicas...

Tabela 2. Estimativa de parâmetros ajustados para temperaturas e umidade relativa do ar para os períodos em função de níveis de umidade aplicados nas pilhas de compostagem

\begin{tabular}{|c|c|c|c|c|c|}
\hline \multicolumn{6}{|c|}{ Temperatura } \\
\hline \multirow{3}{*}{ Período } & \multirow{2}{*}{ Umidade } & \multicolumn{3}{|c|}{ Parâmetros do modelo ${ }^{1}$} & \multirow[b]{2}{*}{$\mathrm{R}^{2}$} \\
\hline & & $a^{3}$ & $\mathrm{~b}^{4}$ & $\mathrm{x}_{0}^{5}$ & \\
\hline & $\%$ & ${ }^{\circ} \mathrm{C}$ & & S ---- & \\
\hline \multirow{4}{*}{ Transição } & 30 & $58,58 * *$ & $5,29 * *$ & $2,03 * *$ & 0,90 \\
\hline & 50 & $64,23 * *$ & $3,47 * *$ & $5,99 * *$ & 0,96 \\
\hline & 70 & $65,63 * *$ & $3,37 * *$ & $4,62 * *$ & 0,97 \\
\hline & 30 & $66,63 * *$ & $3,57 * *$ & $4,73 * *$ & 0,95 \\
\hline \multirow[t]{2}{*}{ Seco } & 50 & $61,75 * *$ & $3,83 * *$ & $4,12 * *$ & 0,95 \\
\hline & 70 & $59,93 * *$ & $4,45^{* *}$ & $3,94 * *$ & 0,93 \\
\hline \multirow{3}{*}{ Chuvoso } & 30 & $58,05 * *$ & $5,53 * *$ & $2,19 * *$ & 0,91 \\
\hline & 50 & $72,20 *$ & $12,81 *$ & $0,01 *$ & 0,85 \\
\hline & 70 & $54,98 *$ & $6,84 *$ & $0,71 *$ & 0,75 \\
\hline \multirow{2}{*}{\multicolumn{6}{|c|}{$\begin{array}{l}\text { Umidade relativa do ar } \\
\qquad \text { Parâmetros do modelo }{ }^{2}\end{array}$}} \\
\hline & & & & & \\
\hline \multirow[t]{3}{*}{ Período } & Umidade & $\mathrm{y}_{0}$ & $\mathrm{a}$ & $\mathrm{b}$ & $\mathrm{R}^{2}$ \\
\hline & ------ \% & --- & ------ c & ----- & \\
\hline & 30 & 68,97 & $-0,18$ & $-0,0011$ & 0,52 \\
\hline \multirow[t]{3}{*}{ Transição } & 50 & 65,57 & $-0,18$ & $-0,0004$ & 0,38 \\
\hline & 70 & $66,11 *$ & $-0,30$ & $-0,000097$ & 0,50 \\
\hline & 30 & $24,10^{*}$ & $0,23^{*}$ & - & 0,49 \\
\hline \multirow[t]{3}{*}{ Seco } & 50 & $24,11 *$ & $0,23 *$ & - & 0,47 \\
\hline & 70 & $24,63^{*}$ & $0,27 *$ & - & 0,47 \\
\hline & 30 & $63,29 *$ & $0,0764^{\mathrm{ns}}$ & $-0,0019$ & 0,47 \\
\hline \multirow[t]{2}{*}{ Chuvoso } & 50 & $53,19 *$ & $0,22 *$ & $-0,0053$ & 0,49 \\
\hline & 70 & $64,90 *$ & $0,22 *$ & $-0,0041$ & 0,64 \\
\hline
\end{tabular}

$\left.{ }^{1} \mathrm{y}=\mathrm{ae}\left(-0,5\left(\left(\ln \left(\mathrm{x} / \mathrm{x}_{\mathrm{o}}\right)\right) / \mathrm{b}\right)^{2}\right)\right) ;{ }^{2} \mathrm{y}=\mathrm{y}_{0}+\mathrm{bx}+\mathrm{ax}^{2}$ ou $\mathrm{y}=\mathrm{y}_{0}+\mathrm{ax} ;{ }^{3}$ valor de máxima temperatura (válido para a equação de pico lognormal); ${ }^{4}$ amplitude do valor de x no período de compostagem entre o ponto de inflexão e o ponto de máxima (válido para a equação de pico lognormal); ${ }^{5}$ dias após a montagem da pilha que proporciona maior temperatura (válido para a equação de pico lognormal).

Tabela 3. Valores médios, teste $\mathrm{F}$ e coeficiente de variação das variáveis redução de massa de carcaça e de pilha compostada, e máxima temperatura observada em função de níveis de umidade (quantidade de água adicionada) e épocas de montagem da pilha

\begin{tabular}{cccc}
\hline Umidade $(\mathrm{U})$ & Carcaça & Pilha compostada & Temperatura máxima \\
\hline$\%$ & $---{ }^{1}$ & ${ }^{\circ} \mathrm{C}$ \\
30 & $88,4 \mathrm{a}^{1}$ & $29,8 \mathrm{~b}$ & $63,5 \mathrm{a}$ \\
50 & $88,2 \mathrm{a}$ & $32,3 \mathrm{~b}$ & $64,2 \mathrm{a}$ \\
70 & $88,5 \mathrm{a}$ & $42,9 \mathrm{a}$ & $62,2 \mathrm{a}$ \\
Teste F & $0,04^{\mathrm{ns}}$ & $32,13^{* *}$ & $5,69^{\mathrm{ns}}$ \\
$\mathrm{CV}_{1}(\%)$ & 2,1 & 10,2 & 2,1 \\
Período $(\mathrm{P})$ & & & \\
Seco & $87,2 \mathrm{a}$ & $31,9 \mathrm{~b}$ & $65,3 \mathrm{a}$ \\
Transição & $89,3 \mathrm{a}$ & $43,5 \mathrm{a}$ & $63,8 \mathrm{a}$ \\
Chuvoso & $88,7 \mathrm{a}$ & $30,6 \mathrm{~b}$ & $60,8 \mathrm{a}$ \\
Teste F & $1,66^{\mathrm{ns}}$ & $35,74^{* *}$ & $1,48^{\mathrm{ns}}$ \\
$\mathrm{CV}_{2}(\%)$ & 2,9 & 10,1 & 8,8 \\
$\mathrm{U} \mathrm{x}_{\mathrm{P}}$ & $3,51^{*}$ & $4,60^{*}$ & $0,78^{\mathrm{ns}}$ \\
\hline
\end{tabular}

${ }^{\text {ns }}, * \mathrm{e}^{* *}$ : não significativo e significativo a 5 e $1 \%$ de probabilidade. ${ }^{1}$ Médias seguidas pela mesma letra na coluna não diferem entre si pelo teste de Tukey $(5 \%)$. 
Com relação ao desdobramento da interação, observa-se que, nos períodos seco e de transição, houve as maiores reduções da massa compostada com a umidade de $70 \%$. Quando se avalia por nível de umidade trabalhado, para a redução de massa de carcaça houve diferença somente para a umidade de $50 \%$, cujo maior valor obtido foi para a época chuvosa; para a redução de massa compostada, independentemente do nível de umidade aplicado, houve superioridade para a época de transição em relação aos demais períodos (Tab. 4). Esse resultado pode ser explicado pelos comportamentos verificados nas Fig. 1 e 2, ou seja, no momento da montagem da pilha, há condições ótimas para o início do processo de compostagem tanto internamente quanto externamente, traduzido pelo período de precipitação, em que, com o passar do tempo, há diminuição da temperatura interna e da umidade relativa do ar, o que se confirma pela diminuição de umidade.

Tabela 4. Médias das variáveis de redução de massa de carcaça e de pilha compostada em função do desdobramento de níveis de umidade (quantidade de água aplicada) e épocas de montagem da pilha

\begin{tabular}{cccc}
\hline & 30 & 50 & 70 \\
\hline Seca & & Carcaça & \\
Transição & $87,5 \mathrm{aA}^{1}$ & $84,6 \mathrm{aB}$ & $89,3 \mathrm{aA}$ \\
Chuvosa & $87,2 \mathrm{aA}$ & $89,6 \mathrm{aAB}$ & $90,2 \mathrm{aA}$ \\
& $90,6 \mathrm{aA}$ & $90,4 \mathrm{aA}$ & $85,8 \mathrm{aA}$ \\
Seca & $27,3 \mathrm{bB}$ & Pilha compostada & $39,8 \mathrm{aB}$ \\
Transição & $36,2 \mathrm{bA}$ & $28,6 \mathrm{bB}$ & $55,8 \mathrm{aA}$ \\
Chuvosa & $25,8 \mathrm{aB}$ & $38,5 \mathrm{bA}$ & $33,3 \mathrm{aB}$ \\
\hline
\end{tabular}

${ }^{\mathrm{T}}$ Médias seguidas pela mesma letra, minúscula na linha e maiúscula na coluna, não diferem entre si pelo teste de Tuky $(5 \%)$.

As reduções verificadas na massa de carcaça estiveram próximas entre as três umidades empregadas. Independentemente do nível de água aplicado, o processo de compostagem de aeração passiva e de fluxo contínuo foi eficiente na eliminação desse resíduo. No entanto, observando os valores de redução da massa compostada, houve valores superiores para a umidade de $70 \%$ em relação às umidades de 50 e $30 \%$. Em trabalho com carcaças de aves, Costa et al. (2006) encontraram reduções de massas de leiras sem revolvimento em torno de $53 \%$, e em composteira sem revolvimento de $21 \%$.

O composto, de modo geral, apresentou-se muito limpo nos aspectos microbiológico e parasitológico, pois, mesmo no início da avaliação (dia 0), poucas amostras ficaram fora dos padrões do CONAMA (Tab. 5).

O período de maior detecção de microorganismos foi na transição, quando foram encontradas altas concentrações de coliformes termotolerantes no dia 0 , porém com eficiente redução após os 120 dias de compostagem. Nos demais períodos, a contagem de coliformes termotolerantes foi baixa e dentro dos padrões desde o início do processo. Quanto à Salmonella, não foi detectada sua presença em nenhuma das amostras analisadas ao longo do experimento.

A detecção de ovos de helmintos nos três períodos foi esparsa, concentrando-se, de certa forma, no período chuvoso, na forma de larvas de Strongyloides de vida livre, mas com o desaparecimento dos helmintos após o processo de compostagem. Esse fato provavelmente se justifica pelo fato de o período chuvoso (umidade elevada e alta temperatura) favorecer a sobrevivência de helmintos no esterco a ser utilizado na formação das pilhas, permitindo a sua detecção no dia 0. 
Tabela 5. Médias das variáveis microbiológicas e patogênicas em função dos níveis de umidade (quantidade de água aplicada), épocas de montagem da pilha e ponto de coleta das amostras

\begin{tabular}{|c|c|c|c|c|c|c|c|c|}
\hline \multirow{2}{*}{ Amostra $^{1}$} & \multirow{2}{*}{ Concentração de patógenos ${ }^{2}$} & \multicolumn{2}{|c|}{ Transição } & \multicolumn{2}{|c|}{ Seca } & \multicolumn{2}{|c|}{ Chuva } & \multirow{2}{*}{ Conama } \\
\hline & & Início (0) & Fim $(120 d)$ & Início (0) & Fim $(120 d)$ & Início (0) & Fim $(120 d)$ & \\
\hline \multirow{3}{*}{$30 \mathrm{~F}$} & $\begin{array}{c}\text { Coliformes termotolerantes } \\
\text { (NMP/g de ST) }\end{array}$ & $\geq 1100$ & $<3$ & $<3$ & $<3$ & $<3$ & $<3$ & $<10^{3}$ \\
\hline & $\begin{array}{c}\text { Ovos viáveis de helmintos } \\
\text { (ovos/g de ST) }\end{array}$ & 0 & 0 & 0 & $<0,25$ & $>0,25$ & 0 & $<0,25$ \\
\hline & Salmonella (em 10g de ST) & ausente & ausente & ausente & ausente & ausente & ausente & ausente \\
\hline \multirow{3}{*}{$30 \mathrm{M}$} & $\begin{array}{l}\text { Coliformes termotolerantes } \\
\text { (NMP/g de ST) }\end{array}$ & $\geq 1100$ & $<3$ & $<3$ & $<3$ & $<3$ & $<3$ & $<10^{3}$ \\
\hline & $\begin{array}{l}\text { Ovos viáveis de helmintos } \\
\text { (ovos/g de ST) }\end{array}$ & 0 & 0 & 0 & 0 & $<0,25$ & 0 & $<0,25$ \\
\hline & Salmonella (em 10g de ST) & ausente & ausente & ausente & ausente & ausente & ausente & ausente \\
\hline \multirow{3}{*}{$30 \mathrm{~S}$} & $\begin{array}{l}\text { Coliformes termotolerantes } \\
\qquad(\mathrm{NMP} / \mathrm{g} \text { de ST })\end{array}$ & $\geq 1100$ & $<3$ & $<3$ & $<3$ & $<3$ & $<3$ & $<10^{3}$ \\
\hline & $\begin{array}{l}\text { Ovos viáveis de helmintos } \\
\text { (ovos/g de ST) }\end{array}$ & 0 & 0 & 0 & 0 & $>0,25$ & 0 & $<0,25$ \\
\hline & Salmonella (em 10g de ST) & ausente & ausente & ausente & ausente & ausente & ausente & ausente \\
\hline \multirow{3}{*}{$50 \mathrm{~F}$} & $\begin{array}{l}\text { Coliformes termotolerantes } \\
\text { (NMP/g de ST) }\end{array}$ & $\geq 1100$ & $<3$ & $<3$ & $<3$ & $<3$ & $<3$ & $<10^{3}$ \\
\hline & $\begin{array}{c}\text { Ovos viáveis de helmintos } \\
\text { (ovos/g de ST) }\end{array}$ & 0 & 0 & 0 & 0 & $>0,25$ & 0 & 0,25 \\
\hline & Salmonella (em 10g de ST) & ausente & ausente & ausente & ausente & ausente & ausente & ausente \\
\hline \multirow{3}{*}{$50 \mathrm{M}$} & $\begin{array}{c}\text { Coliformes termotolerantes } \\
\text { (NMP/g de ST) }\end{array}$ & $\geq 1100$ & $<3$ & $<3$ & $<3$ & $<3$ & $<3$ & $<10^{3}$ \\
\hline & $\begin{array}{c}\text { Ovos viáveis de helmintos } \\
\text { (ovos/g de ST) }\end{array}$ & 0 & 0 & 0 & $<0,25$ & 0 & 0 & $<0,25$ \\
\hline & Salmonella (em 10g de ST) & ausente & ausente & ausente & ausente & ausente & ausente & ausente \\
\hline \multirow{3}{*}{$50 \mathrm{~S}$} & $\begin{array}{l}\text { Coliformes termotolerantes } \\
\text { (NMP/g de ST) }\end{array}$ & $\geq 1100$ & $<3$ & $<3$ & $<3$ & $<3$ & $<3$ & $<10^{3}$ \\
\hline & $\begin{array}{c}\text { Ovos viáveis de helmintos } \\
\text { (ovos/g de ST) }\end{array}$ & 0 & 0 & 0 & 0 & 0 & 0 & $<0,25$ \\
\hline & Salmonella (em 10g de ST) & ausente & ausente & ausente & ausente & ausente & ausente & ausente \\
\hline \multirow{3}{*}{$70 \mathrm{~F}$} & $\begin{array}{l}\text { Coliformes termotolerantes } \\
\text { (NMP/g de ST) }\end{array}$ & $\geq 1100$ & $<3$ & $<3$ & 23 & $<3$ & $<3$ & $<10^{3}$ \\
\hline & $\begin{array}{l}\text { Ovos viáveis de helmintos } \\
\quad \text { (ovos/g de ST) }\end{array}$ & 0 & 0 & 0 & $<0,25$ & 0 & 0 & $<0,25$ \\
\hline & Salmonella (em 10g de ST) & ausente & ausente & ausente & ausente & ausente & ausente & ausente \\
\hline \multirow{3}{*}{$70 \mathrm{M}$} & $\begin{array}{l}\text { Coliformes termotolerantes } \\
\text { (NMP/g de ST) }\end{array}$ & $\geq 1100$ & $<3$ & $<3$ & $<3$ & $<3$ & $<3$ & $<10^{3}$ \\
\hline & $\begin{array}{l}\text { Ovos viáveis de helmintos } \\
\text { (ovos/g de ST) }\end{array}$ & 0 & $<0,25$ & $>0,25$ & 0 & 0 & 0 & $<0,25$ \\
\hline & Salmonella (em 10g de ST) & ausente & ausente & ausente & ausente & ausente & ausente & ausente \\
\hline \multirow[b]{2}{*}{$70 \mathrm{~S}$} & $\begin{array}{l}\text { Coliformes termotolerantes } \\
\text { (NMP/g de ST) }\end{array}$ & $\geq 1100$ & $<3$ & $<3$ & $<3$ & $<3$ & $<3$ & $<10^{3}$ \\
\hline & $\begin{array}{l}\text { Ovos viáveis de helmintos } \\
\quad \text { (ovos/g de ST) } \\
\text { Salmonella (em 10g de ST) }\end{array}$ & $\begin{array}{c}0 \\
\text { ausente }\end{array}$ & $\begin{array}{c}0 \\
\text { ausente }\end{array}$ & $\begin{array}{c}<0,25 \\
\text { ausente }\end{array}$ & $\begin{array}{c}0 \\
\text { ausente }\end{array}$ & $\begin{array}{c}0 \\
\text { ausente }\end{array}$ & $\begin{array}{c}0 \\
\text { ausente }\end{array}$ & $\begin{array}{l}<0,25 \\
\text { ausente }\end{array}$ \\
\hline
\end{tabular}

Nota: ${ }^{1}$ Umidade - 30, 50 e 70\%; localização na pilha - F: fundo, M: meio e S: superfície. ${ }^{2} \mathrm{NMP}$ : número mais provável; ST: sólidos totais.

O processo de compostagem de aeração passiva e fluxo contínuo permitiu elevados valores de temperatura $\left(60,8\right.$ a $\left.65,3^{\circ} \mathrm{C}\right)$ nas diferentes condições de umidade da pilha e período climático de avaliação, e principalmente a manutenção da temperatura elevada (superior a $50^{\circ} \mathrm{C}$ ) por mais de 45 dias, mesmo sendo alimentada em fluxo contínuo e não sofrendo revolvimento. Essa temperatura elevada por longo período permite a destruição dos patógenos, conforme também foi observado por outros autores (Orrico et al., 2007; Orrico Júnior et al., 2010). O processo desses autores, como o sistema de compostagem incluiu o revolvimento, 
exigiu que eles realizassem uma précompostagem das carcaças, tornando-o mais complexo. A vantagem do presente processo é a não necessidade de pré-compostagem e a não exposição das carcaças ao ambiente. Analisandose os dados em seu conjunto, observa-se que, de modo geral, o material de construção das pilhas não apresentava altas concentrações de patógenos, exceto pelos coliformes termotolerantes, que são esperados nas fezes. Mas, ao final do processo, todas as amostras ficaram dentro dos padrões estabelecidos pelo Conama, indicando que a compostagem promove a eliminação dos patógenos avaliados e o composto poderia ser utilizado de forma segura. Ressalta-se que o processo de fluxo contínuo não permite o revolvimento do material, no entanto a troca de calor no interior da pilha ocorre por convecção, o que implica o uso de materiais com granulometria adequada e o local de montagem com estrutura que permita entrada e saída de ar, como tábuas encaixadas.
Os valores de referência para substâncias inorgânicas, segundo a Resolução Normativa n³75 de 2006 do CONAMA (Brasil, 2006) e de características químicas para fertilizantes orgânicos e compostos da Instrução Normativa $\mathrm{n}^{\circ} 25$ de 2009 do MAPA (Brasil, 2009) estão apresentados na Tab. 6, com os atributos do composto orgânico para essas variáveis e outros elementos não contemplados em ambas as especificações, cujos resultados indicam que o composto atende os critérios para aplicação e uso como fertilizante orgânico. Ressalta-se que foi utilizada como parâmetro a legislação de lodo de esgoto, a qual apresenta limites máximos para a presença de metais pesados em lodos, pois atualmente não há tabelas que referenciem a produção de compostos orgânicos de origem animal (no caso resíduos: carcaças e despojos de abate).

Tabela 6. Valores médios de substâncias inorgânicas do composto proveniente de resíduos da produção e do abate de pequenos ruminantes e valores balizadores da Resolução ${ }^{\circ}$ 375, de 2006, do CONAMA, e da Instrução Normativa ${ }^{\circ} 25$, de 2009, do MAPA

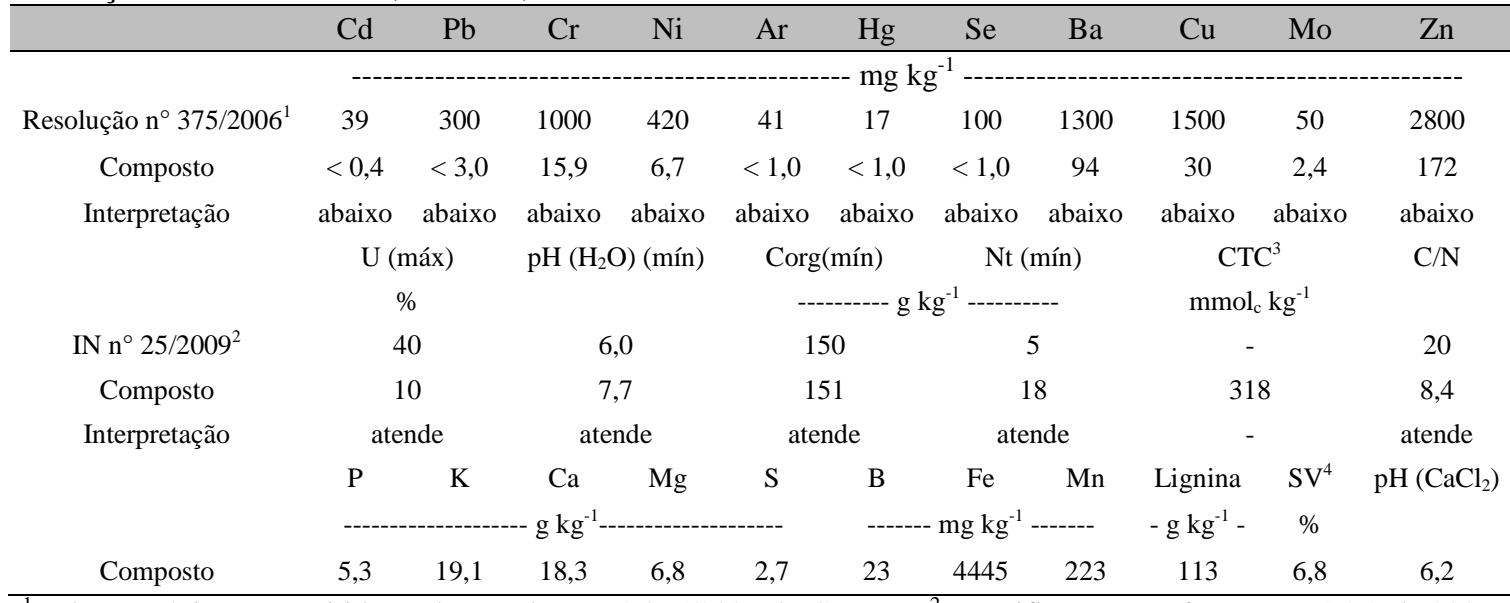

${ }^{1}$ Valores máximos permitidos pela Resolução $\mathrm{n}^{\circ} 375 / 2006$ do Conama. ${ }^{2}$ Especificações conforme $\mathrm{IN}^{\circ}{ }^{25}$, de 2009, do Mapa, valores balizadores segundo composto classe "D". ${ }^{3} \mathrm{CTC}$ - segundo IN no 25, de 2009, conforme declarado. SV - sólidos voláteis. U - umidade; máx - máximo; mín - mínimo.

Ainda, a Instrução Normativa $\mathrm{n}^{\circ} 8$ de 2004 , do MAPA (Brasil, 2004) proíbe, em todo o território nacional, a produção, a comercialização e a utilização de produtos destinados à alimentação de ruminantes que contenham, em sua composição, proteínas e gorduras de origem animal. Dessa forma, o composto orgânico pode ter sua utilização destinada como fertilizante orgânico/composto. Ainda, a IN no 25 de 2009, do MAPA (Brasil, 2009) cita que o uso de compostos de resíduo de origem animal e da criação de animais é permitido em pastagens e capineiras apenas com incorporação ao solo; no caso de pastagens, é permitido o pastoreio somente depois de 40 dias da incorporação do fertilizante ao solo. Os dados do presente estudo permitem que o composto orgânico proveniente de resíduos da produção e do abate de pequenos 
ruminantes poderia ser empregado com menos dias que o citado na respectiva norma.

\section{CONCLUSÕES}

O processo de compostagem de resíduos da produção e do abate de pequenos ruminantes é alternativa viável para o tratamento de resíduos da produção animal. O composto orgânico gerado atende as especificações das legislações utilizadas para comparação. Independentemente da época do ano ou da umidade aplicada, o processo de compostagem foi eficiente em reduzir passivos ambientais, como carcaças. A compostagem promoveu a eliminação dos patógenos avaliados, indicando que o composto não oferece risco de transmissão e pode ser utilizado de forma segura. A aplicação da umidade de $50 \%$ com base no peso das carcaças pode ser empregada em todas as épocas estudadas, com manutenção do comportamento da temperatura ao longo da compostagem.

\section{REFERÊNCIAS}

ABREU, M.F.; ANDRADE, J.C.; FALCÃO, A.A. Protocolos de análises químicas. In: ANDRADE, J.C.; ABREU, M.F. Análise química de resíduos sólidos para monitoramento e estudos agroambientais. Campinas: Instituto Agronômico, 2006. p.121-158.

ABREU, P.G. et al. Casca de arroz e palhada de soja na compostagem de carcaças de frango de corte. Acta Sci. Anim. Sci., v.33, p.51-57, 2011.

ANDREWSW, H.; HAMMACK, T.S. Bacteriological analytical manual. 8.ed. New Hampshire: FDA, 2007. chap.5.21. Available in: <http://www.fda.gov/downloads/Food/FoodScienceRe search/UCM244774.pdf >. Accessed in: 03 fevereiro de 2017.

ANGONESE, A.R. et al. Eficiência energética de sistema de produção de suínos com tratamento dos resíduos em biodigestor. Rev. Bras. Eng. Agríc. Ambient., v.10, p.745-750, 2006.

ANUÁRIO BRASILEIRO DA PECUÁRIA. São Paulo: FNP, 2014. 313p.

BRASIL. Ministério da Agricultura, Pecuária e Abastecimento. Serviço de Defesa Animal. Instrução Normativa $n^{\circ} 8$ de 25 de março de 2004. Proibe em todo o território nacional a produção, a comercialização e a utilização de produtos destinados à alimentação de ruminantes que contenham em sua composição proteínas e gorduras de origem animal.
Diário Oficial da União, Brasília, DF, 26 de março de 2004. Seção 1. p. 5.

BRASIL. Conselho Nacional de Meio Ambiente CONAMA. Resolução $n^{\circ} 375$, de 29 de agosto de 2006. Define critérios e procedimentos, para uso agrícola de lodos de esgoto gerados em estações de tratamento de esgoto sanitário e seus produtos derivados, e dá outras providências. Diário Oficial da União, Brasília, DF, 30 de agosto de 2006. Seção 1. p.141-146.

BRASIL. Ministério da Agricultura Pecuária e Abastecimento. Secretaria de Defesa Agropecuária. Instrução Normativa ${ }^{\circ} 25$ de 23 de julho de 2009. Estabelece as normas sobre as especificações e as garantias, as tolerâncias, o registro, a embalagem e a rotulagem dos fertilizantes orgânicos simples, mistos, compostos, organominerais e biofertilizantes destinados à agricultura. Diário Oficial da República Federativa do Brasil, Brasília, DF, de 28 julho de 2009. Seção 1, p. 20.

COSTA, M.S.S.M. et al. Desempenho de quatro sistemas para compostagem de carcaça de aves. Rev. Bras. Eng. Agríc. Ambient., v.10, p.692-698, 2006.

CURCI, V.C.L.M. et al. Pré-compostagem de cadáveres de bovinos acometidos pelo botulismo. Pesqui. Vet. Bras., v.27, p.157-161, 2007.

FERREIRA, D.F. SISVAR: A computer statistical analysis system. Ciênc. Agrotec., v.35, p.1.039-1.042, 2011.

GORDON, H.McL.; WHITLOCK, H.V. A new technique for counting nematode eggs in sheep faeces. J. Council Sci. Ind. Res., v.12, p.50-52, 1939.

HECK, K. et al. Temperatura de degradação de resíduos em processo de compostagem e qualidade microbiológica do composto final. Rev. Bras. Eng. Agríc. Ambient., v.17, p.54-59, 2013.

KORNACKI, J.L.; JOHNSON, J.L. Enterobateriaceae, coliforms and Escherichia coli as quality and safety indicators. In: VANDERZANT, C.; SPLITTSTOESSER, D.F. Compendium of methods for the microbiological examination of foods. 4.ed. Washington: American Public Health Association, 2001. cap.8, p.69-82.

MIYATAKE, F.; IWABUCHI, K. Effect of compost temperature on oxygen uptake rate, specific growth rate and enzymatic activity of microorganisms in dairy cattle manure. Bioresour. Technol., v.97, p.961-965, 2006.

MURRAY, D. et al. Transgene and mitochondrial DNA are indicators of efficient composting of transgenic pig carcasses. Bioresour. Technol., v.98, p.1795-1804, 2007. 
ORRICO JÚNIOR, M.A.P.; ORRICO, A.C.A.; LUCAS JÚNIOR, J. Compostagem dos resíduos da produção avícola: cama de frangos e carcaças de aves. Eng. Agríc., v.30, p.538-545, 2010.

ORRICO, A.C.A.; LUCAS JÚNIOR, J.; ORRICO JÚNIOR, M.A.P. Alterações físicas emicrobiológicas durante a compostagem dos dejetos de cabras. Eng. Agríc., v.27, p.764-772, 2007

OTENIO, M.R.; CUNHA, C.M.; ROCHA, B.B. Compostagem de carcaças de grandes animais. Juiz de Fora: Embrapa Gado de Leite, 2010. 4p. (Comunicado Técnico, 61).
SOUZA, H.A. et al. Dose econômica e eficiência agronômica de composto orgânico proveniente de resíduos da proveniente de resíduos da criação e abate de pequenos ruminantes $e$ de adubo nitrogenado na produção de milho em Luvissolo Háplico, no semiárido cearence. Sobral: Embrapa Caprinos e Ovinos, 2015. 10p. (Comunicado Técnico, 144)

VALENTE, B.S. et al. Fatores que afetam o desenvolvimento da compostagem de resíduos orgânicos. Arch. Zootec., v.58, p.59-85, 2009. 